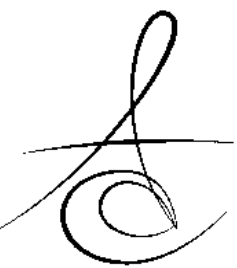

\title{
ÜÇÜNCÜ MOLARLARIN MİNERALİZASYON VE ERÜPSİYON AŞAMALARININ 18 YAŞ SINIRI TAHMİN DOĞRULUĞU*
}

\section{ACCURACY OF THE MINERALIZATION AND ERUPTION STAGES IN THE THIRD MOLARS TO ESTIMATE THE 18-YEAR THRESHOLD*}

\author{
Dr. Öğr. Üy. Hümeyra Özge YILANCI*
}

\author{
Dr. Öğr. Üy. Nursel AKKAYA**
}

\author{
Makale Kodu/Article code: 4863 \\ Makale Gönderilme tarihi: 11.02 .2021 \\ Kabul Tarihi: 18.03.2021
}

DOI : $10.17567 /$ ataunidfd.900944
Hümeyra Özge Yılanci: ORCID ID: 0000-0002-9620-9292

Nursel Akkaya: ORCID ID: 0000-0002-2854-1138

\section{öz}

Amaç: Hukuki ve cezai sorumluluğun belirlenmesinde yasal yaş sınırları önemlidir. Çocukların yetişkinlerden ayırt edilmesinde bireylerin 18 yaşını doldurmuş olup olmadığı dikkate alınır. Bu çalışmanın amacı, üçüncü molarların mineralizasyon ve erüpsiyon aşamalarının 18 yaşı ayırt etmede doğruluğunun test edilmesi ve her ikisinin birlikte kullanımasının 18 yaş tahmin performansına etkisinin incelenmesidir.

Gereç ve Yöntem: Çalışmaya 13-24 yaş aralığında 449 hastanın panoramik radyogramı dahil edildi. Maksiller ve mandibular üçüncü molarların mineralizasyon aşamaları Demirjian yöntemine göre $\mathrm{A}-\mathrm{H}$ arasında, erüpsiyon aşamaları Olze yöntemine göre A-D arasında derecelendirildi. Her iki yöntem için 18 yaşı gösteren eşik aşamalar belirlendi. Belirlenen eşik aşamaların tek başına ve birlikte kullanımının 18 yaş tahmin performansları ROC (Receiver Operating Characteristic) analizi ile değerlendirildi.

Bulgular: Üçüncü molarların mineralizasyon ve erüpsiyon aşamalarında sağ ile sol taraf arasında anlamlı farklılık bulunmazken, maksiller molarların mandibular molarlara göre mineralizasyonda ileri aşamada olduğu ve erüpsiyonda geciktiği saptandı. Mineralizasyon ve erüpsiyon yöntemine göre eşik aşamalar sırasıyla maksiller molarlarda H ve B, mandibular molarlarda $\mathrm{G}$ ve $\mathrm{C}$ olarak belirlendi. Tüm üçüncü molarların erüpsiyon aşamaları 18 yaşın ayırt edilmesinde \%87 doğruluk sağlarken, mineralizasyon aşamaları \%89-92 arasında değişen düzeylerde doğruluk gösterdi. Her iki yöntem birlikte kullanıldığında ise doğruluğun \%87-89 arasında değiştiği gözlendi.

Sonuç: Mineralizasyon ve erüpsiyon yöntemleri, 18 yaş tahmininde yüksek ve orta düzey doğrulukta sonuç veren ilave metotlar olarak adli uygulamalarda yararlı olabilir. Bununla birlikte üçüncü molarların erüpsiyon aşamalarının, mineralizasyon aşamaları ile yapılan 18 yaş sınırı tahmin performansına anlamlı bir katkısı bulunmamıştır.

Anahtar kelimeler: Dişlerden yaş tespiti; Diş kalsifikasyonu; Panoramik radyografi; Çocuk; Erişkin.

\section{ABSTRACT}

Aim: Legal age thresholds are important to clarify legal and criminal liability. For discriminating children from adults, it is taken into account whether individuals have attained the age of 18 years. The aim of this study was to test the accuracy of the mineralization and eruption stages of the third molars for the discrimination of the age of 18 years and to examine the effect of the combined use of both indicators on the prediction performance.

Materials and Methods: Panoramic radiographs of 449 patients aged between 13 and 24 years were included in the study. The mineralization stages of the maxillary and mandibular third molars were scored ranged from $\mathrm{A}$ to $\mathrm{H}$ using Demirjian method, and the eruption stages ranged from $A$ to $D$ using Olze method. The cut-offs of the stages for both methods were determined in terms of the age threshold of 18 years. The performance of the identified cut-offs individually and in combination for the prediction of the age of 18 years was evaluated by ROC (Receiver Operating Characteristic) analysis.

Results: There was no significant difference between the right and left sides in the mineralization and eruption stages of the third molars while it was found that the maxillary molars were advanced in mineralization and delayed in eruption compared to the mandibular molars. The cut-offs of the mineralization and eruption stages were determined as $\mathrm{H}$ and $\mathrm{B}$ in maxillary molars, $\mathrm{G}$ and $\mathrm{C}$ in mandibular molars, respectively. The eruption stages of all third molars provided an accuracy of $87 \%$ in the discrimination of the age of 18 years while the mineralization stages showed accuracy ranging from $89 \%$ to $92 \%$. When both methods were used in combination, it was observed that the accuracy varied between $87 \%$ and $89 \%$.

Conclusion: The mineralization and eruption methods can be useful in forensic practice as supplementary methods with high and moderate accuracy for the estimation of the age of 18 years. However, the eruption stages of the third molars did not significantly contribute to the prediction performance of the mineralization stages for the age threshold of 18 years.

Keywords: Age determination by teeth; Tooth calcification; Panoramic radiography; Child; Adult.

*İzmir Demokrasi Üniversitesi, Diş Hekimliği Fakültesi, Ağız Diş ve Çene Radyolojisi Anabilim Dalı, Konak, İzmir **Hacettepe Üniversitesi, Diş Hekimliği Fakültesi, Ağız Diş ve Çene Radyolojisi Anabilim Dall, Sıhhiye, Ankara

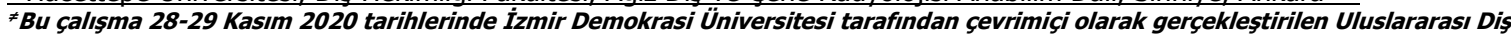
Hekimliğgi ve Sağlık Kongresi'nde sözlü sunum olarak sunulmus ve kongre kitapçı̆ğında özeti yayınlanmıstır.

Kaynakça Bilgisi: Yılancı HÖ, Akkaya N. Üçüncü molarların mineralizasyon ve erüpsiyon aşamalarının 18 yaş sınırı tahmin doğruluğu. Atatürk Üniv Diş Hek Fak Derg 2021; 31: 160-6.

Citation Information: Yllanci HO, Akkaya N. Accuracy of the mineralization and eruption stages in the third molars to estimate the 18-year threshold. J Dent Fac Atatürk Uni 2021; 31: 160-6. 


\section{GİRİŞ}

Yaş tahmini adli bilimlerde bireyin hukuki ve cezai sorumluluğunun belirlenmesinde, kimliği belirsiz ve şüpheli ölümlerde, antropolojide insan kalıntılarının biyolojik profilinin oluşturulmasında gerekli olan bir uygulamadır. Askerlik, evlilik, işe girme, emeklilik ve spor müsabakaları gibi nedenlerle de yaş tayini gerekebilir. Ülkemizde genellikle nüfus kayıtlarının düzenli tutulmamasından dolayı yapılan bu incelemeye, son yıllarda geçerli kimlik belgesi olmayan sığınmacı sayısının artış göstermesi ile daha fazla ihtiyaç duyulmaktadır. ${ }^{1-5}$

Bireyin kronolojik yaşına en yakın yaş tahminini yapabilmek amacıyla çeşitli fiziksel gelişim ölçütleri ve yaşlanma bulgularından yararlanılır. ${ }^{6}$ Uluslararası ve Disiplinlerarası Adli Yaş Tayini Çalışma Grubu'nun (AGFAD) önerilerine göre yaş tahmini uygulamalarında fizik muayene (antropometrik inceleme, cinsiyet özelliği bulguları, hormonal bozukluklar), sol elin radyografik incelemesi ve dental muayene (klinik ve panoramik radyografik inceleme) bulguları kombine edilmelidir. ${ }^{7}$

Bebeklik, çocukluk ve adolesan dönemlerde dental yöntemlerin yaş tahmin doğruluğu oldukça yüksek olmasına karşın, ${ }^{8,9}$ yaşın artmasıyla bu yöntemlerin doğruluğu azalmaktadır. ${ }^{10}$ İskeletsel büyüme ve gelişimin sonuna doğru genç erişkinlerde matürasyonunu görece geç tamamlayan klavikula, el kemikleri ve iliak krestin apofizi ${ }^{11}$ ve ek bir radyolojik değerlendirme olarak üçüncü molar gelişimi yaş tayini için yararlı olabilmektedir. ${ }^{12}$

Erişkinlikte yaş tahmininde en önemli konu çocukların erişkinlerden ayırt edilmesidir. Türk Ceza Kanunu hükümlerine göre on sekiz yaşını doldurmamış birey çocuktur. ${ }^{13} \mathrm{Bu}$ nedenle yaş tahmininden çok bireyin 18 yaşını doldurup doldurmadığının belirlenebilmesi önem kazanmaktadır.

18 yaş tahmini için üçüncü molar gelişiminin ölçütü olarak mineralizasyon ya da erüpsiyon derecesi kullanılabilir. Mineralizasyon, radyografik derecelendirme sistemleri ${ }^{14}$ ya da ölçüme dayalı yöntemler ${ }^{15}$ ile değerlendirilir. Erüpsiyon ise klinik ve radyografik olarak gözlemlenebilir. Derecelendirme sistemleri pratik olması ve teknik donanım gerektirmemesi bakımından adli uygulamalarda kolaylık sağlamaktadır. ${ }^{16}$ Mineralizasyonun değerlendirilmesinde Demirjian yöntemi ${ }^{17}$ diş gelişim aşamalarına dayalı diğer derecelendirme sistemlerine göre hem gözlemci uyumu hem de tanımlanan aşamalar ile gerçek yaş arasındaki korelasyonun yüksek olması nedeniyle tercih edilen bir yöntemdir. ${ }^{18}$ Çocuklarda ve adolesanlarda kullanılmak üzere geliştirilen bu yöntem mandibular üçüncü molar dışındaki yedi dişin kron ve kök mineralizasyon derecesini A-H arasında sekiz aşamada sınıflandırır. Mincer ve ark. ${ }^{19}$ Demirjian yöntemini üçüncü molarlarda uygulamışlardır. Daha sonra yaş tahmini için üçüncü molar mineralizasyon aşamalarının kullanı- mı çeşitli çalışmalarda incelenmiştir. ${ }^{18,20,21}$ Gambier ve ark. ${ }^{16}$ mineralizasyon değerlendirilmesinin güç olduğu durumlarda ve özellikle zaman sıkıntısı olan adli uygulamalarda erüpsiyon yönteminin iyi bir alternatif olduğunu rapor etmişlerdir. Erüpsiyonun radyografik derecelendirmesi için ise genelde Olze ve ark.'nın ${ }^{22}$ A-D arasında dört aşama içeren yöntemi kullanılmıştır.

Çalışmamızda, üçüncü molarların mineralizasyon ve erüpsiyon aşamalarının 18 yaşı ayırt etmede doğruluğunun test edilmesi ve her iki yöntemin birlikte kullanılmasının 18 yaş tahmin performansına etkisinin araştırılması amaçlanmıştır.

\section{GEREÇ VE YÖNTEM}

Çalışmamız Hacettepe Üniversitesi Girişimsel Olmayan Klinik Araştırmalar Etik Kurulu tarafından onaylandı ve Helsinki Deklarasyonu prensiplerine uygun olarak yapıldı. Hacettepe Üniversitesi Diş Hekimliği Fakültesi dijital görüntü arşivinden 2014-2016 yıllarında elde edilmiş olan panoramik radyogramlar incelenerek 13-24 yaş aralığında olan, dahil etme ölçütlerini karşılayan görüntüler seçildi. Dahil etme ölçütleri; radyografik kalitenin diagnostik olarak uygun olması, tüm üçüncü molarların mevcut olması, üçüncü molarların belirgin morfolojik ya da pozisyonel anomalisinin olmaması, ilgili bölgede patoloji, fraktür gibi incelemeye engel olabilecek durumların bulunmaması olarak belirlendi. Seçim ölçütlerini karşılayan 449 radyogram rastgele numaralandırıldı. Radyogramları çalışmaya dahil edilen hastaların yaş ve cinsiyet bilgileri kaydedildi. Kronolojik yaş, radyografinin alındığı tarihten doğum tarihi çıkarılarak ondalık sistemde hesaplandı. Numaralandırılmış panoramik radyogramlarda her bir üçüncü moların mineralizasyon aşamaları Demirjian ve $\operatorname{ark'nın~}^{17}$ (Şekil 1), erüpsiyon aşamaları ise Olze ve $\operatorname{ark}^{\prime} ı^{22}$ (Şekil 2) panoramik radyogramlar için kullandığı sınıflandırma sistemine göre derecelendirildi.

Gözlemci içi ve gözlemciler arası tutarlılığı test etmek için, değerlendirmeler tamamlandıktan 2 ay sonra rastgele seçilen 50 radyogram tekrar derecelendirildi.

Tüm analizler SPSS v21 programında (IBM Corp., Armonk, NY, USA) yapıldı. Gözlemci içi ve gözlemciler arası uyumu değerlendirmek için kappa 
testi uygulandı. Cinsiyetler arası fark ki-kare testi ile incelendi ve dişler arası farkın incelenmesi için ikili karşılaştırmalar Bonferroni düzeltmesi ile yapıldı. Yaş gruplarını tahmin etmek için model oluşturmak amacıyla çoklu lojistik regresyon analizi yapıldı. Yöntemlerin dişlere göre yaş gruplarını tahmin etme performansı Receiver Operating Characteristic (ROC) analizi ile değerlendirildi. $P<0,05$ değerleri istatistiksel olarak anlamlı sonuç kabul edildi.

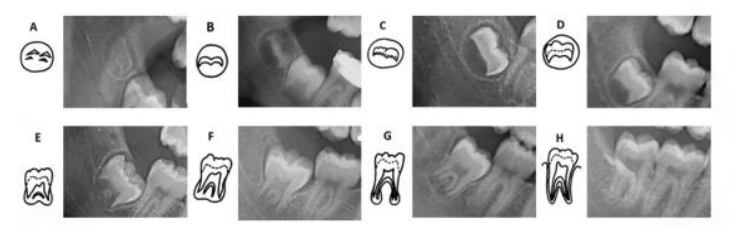

Şekil 1. Demirjian ve ark.'nın ${ }^{17}$ yöntemine göre üçüncü molarların mineralizasyon aşamalarının $\mathrm{A}-\mathrm{H}$ arasında derecelendirilmesi

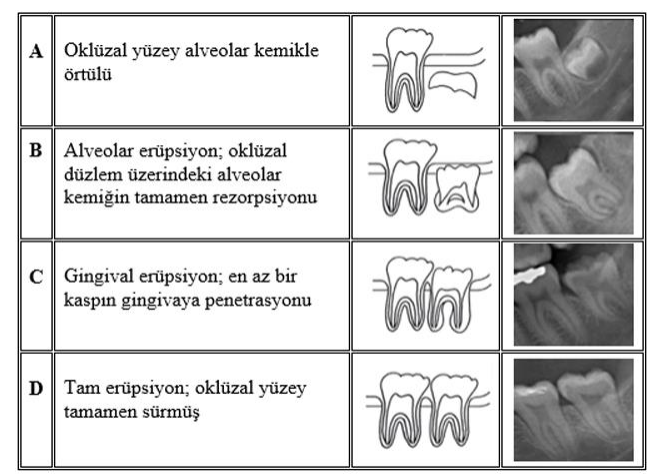

Şekil 2. Olze ve ark.'nın ${ }^{22}$ yöntemine göre üçüncü molarların erüpsiyon aşamalarının A-D arasında derecelendirilmesi

\section{BULGULAR}

Çalışmaya dahil edilen 449 hastanın 244'ü kadın ve $205^{\prime i}$ erkekti. 12,16 - 23,82 yaş aralığındaki hastaların ortalama yaşı $16,92 \pm 3,04$ idi. 160 (\%35,63) hasta 18 yaşında veya üstündeydi. Çalışmaya dahil edilen bireylerin yaş ve cinsiyete göre dağılımı Tablo 1 'de sunulmuştur.

Demirjian metodunda gözlemci içi uyum için kappa katsayısı dişlere göre 0,899-0,924 değerleri arasında değişmekte iken, gözlemciler arası uyum için 0,726-0,824 arasında bulundu. Olze metodu için gözlemci içi uyum için kappa katsayısı 0,889-1,000, gözlemciler arası uyum için ise diş tiplerine göre 0,726-1,000 arasında bulundu. Landis ve Koch'un ${ }^{23}$ sınıflandırmasına göre kappa katsayısı 0,61-0,80 aralığında güçlü uyumu ve $0,81-1,00$ aralığında ise mükemmel uyumu temsil etmektedir.
18 yaş altı grupta cinsiyetler arası farklılık izlenmezken ( $p>0,05), 18$ yaş ve üstü grupta sadece mineralizasyon $\mathrm{H}$ ve erüpsiyon $\mathrm{D}$ aşaması frekanslarının erkeklerde istatistiksel olarak daha fazla olduğu bulundu $(p<0,05)$. Tüm dişler için mineralizasyon aşamalarına ilişkin yaşa ait tanımlayıcı istatistikler Tablo 2'de, erüpsiyon aşamalarına ilişkin yaşa ait tanımlayıcı istatistikler ise Tablo 3'te sunulmuştur.

Tablo 1. Bireylerin yaş ve cinsiyete göre dağılımı

\begin{tabular}{|l|l|l|l|}
\hline Yaş (yıl) & Kadın & Erkek & Toplam \\
\hline $12,00-12,99$ & 15 & 21 & 36 \\
\hline $13,00-13,99$ & 28 & 30 & 58 \\
\hline $14,00-14,99$ & 26 & 22 & 48 \\
\hline $15,00-15,99$ & 32 & 29 & 61 \\
\hline $16,00-16,99$ & 29 & 29 & 58 \\
\hline $17,00-17,99$ & 16 & 12 & 28 \\
\hline $18,00-18,99$ & 23 & 11 & 34 \\
\hline $19,00-19,99$ & 30 & 13 & 43 \\
\hline $20,00-20,99$ & 16 & 9 & 25 \\
\hline $21,00-21,99$ & 13 & 13 & 26 \\
\hline $22,00-22,99$ & 9 & 11 & 20 \\
\hline $23,00-23,99$ & 7 & 5 & 21 \\
\hline Toplam & 244 & 205 & 449 \\
\hline
\end{tabular}

Tablo 2. Mineralizasyon aşamalarına göre her bir diş tipi için tanımlayıcı istatistikler

\begin{tabular}{|l|l|l|l|l|l|l|}
\hline Așama & Diş & N & Ort & SS & Min & Maks \\
\hline C & 18 & 12 & 13,15 & 1,06 & 12,16 & 15,56 \\
& 28 & 12 & 13,02 & 1,21 & 12,16 & 16,62 \\
& 38 & 28 & 13,36 & 1,82 & 12,16 & 21,85 \\
& 48 & 26 & 13,09 & 0,83 & 12,16 & 15,67 \\
\hline D & 18 & 82 & 14,02 & 1,60 & 12,29 & 21,85 \\
& 28 & 74 & 13,98 & 1,64 & 12,19 & 21,85 \\
& 38 & 72 & 14,10 & 1,32 & 12,43 & 19,09 \\
& 48 & 77 & 14,31 & 1,62 & 12,39 & 21,85 \\
\hline E & 18 & 106 & 15,05 & 1,53 & 12,66 & 20,15 \\
& 28 & 112 & 15,09 & 1,58 & 12,66 & 20,15 \\
& 38 & 108 & 15,32 & 1,65 & 12,83 & 20,15 \\
& 48 & 102 & 15,18 & 1,58 & 12,74 & 20,15 \\
\hline F & 18 & 39 & 16,17 & 1,50 & 13,33 & 19,64 \\
& 28 & 41 & 16,10 & 1,53 & 13,33 & 19,64 \\
& 38 & 47 & 16,22 & 1,37 & 13,80 & 19,89 \\
& 48 & 44 & 16,27 & 1,28 & 14,00 & 19,34 \\
\hline G & 18 & 72 & 17,68 & 2,03 & 14,50 & 23,22 \\
& 28 & 62 & 17,55 & 2,04 & 14,50 & 23,22 \\
& 38 & 76 & 17,90 & 1,90 & 15,07 & 23,79 \\
& 48 & 77 & 17,95 & 1,85 & 15,23 & 23,22 \\
\hline H & 18 & 138 & 20,22 & 1,92 & 15,07 & 23,82 \\
& 28 & 148 & 20,05 & 2,02 & 15,07 & 23,82 \\
& 38 & 117 & 20,66 & 1,65 & 16,19 & 23,82 \\
& 48 & 120 & 20,58 & 1,75 & 15,07 & 23,82 \\
\hline
\end{tabular}

* N: sayı, Ort: ortalama, SS: standart sapma, Min: minimum, Maks: maksimum

Üçüncü molarların mineralizasyon ve erüpsiyon aşamalarında sağ ile sol taraf arasında istatistiksel olarak anlamlı farklılık bulunmazken, maksilla ve mandibula arasında anlamlı fark olduğu bulundu (Tablo 4). Maksiller molarların mandibular molarlara göre mineralizasyonda ileri aşamada olduğu ve erüpsiyonda ise geciktiği saptandı.

18 yaş için ayırt edici mineralizasyon ve erüpsiyon eşik aşamaları sırasıyla maksiller üçüncü molarlar

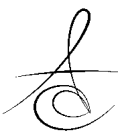


için $\mathrm{H}$ ve $\mathrm{B}$; mandibular üçüncü molarlar için $\mathrm{G}$ ve $\mathrm{C}$ olarak belirlendi. Her bir yöntem ve yöntemlerin kombinasyonu için, diş tiplerine göre belirlenen eşik aşamaların 18 yaş tahmini performans ölçüleri olarak duyarlılık, seçicilik, doğruluğu temsil eden ROC eğrisi altında kalan alan (AUC, area under the ROC curve), pozitif ve negatif olabilirlik oranları ( $L R+$ ve $L R-$, positive and negative likelihood ratios) Tablo 5'te sunulmuştur.

Tablo 3. Erüpsiyon aşamalarına göre her bir diş tipi için tanımlayıcı istatistikler

\begin{tabular}{|l|l|l|l|l|l|l|}
\hline Așama & Diș & N & Ort & SS & Min & Maks \\
\hline A & 18 & 229 & 14,83 & 1,87 & 12,16 & 21,85 \\
& 28 & 227 & 14,81 & 1,82 & 12,16 & 21,85 \\
& 38 & 197 & 14,61 & 1,76 & 12,16 & 21,85 \\
& 48 & 197 & 14,53 & 1,66 & 12,16 & 21,85 \\
\hline B & 18 & 87 & 17,35 & 2,01 & 13,76 & 23,41 \\
& 28 & 88 & 17,48 & 2,16 & 13,76 & 23,41 \\
& 38 & 94 & 16,85 & 1,97 & 13,25 & 21,98 \\
& 48 & 95 & 17,09 & 2,03 & 13,25 & 23,24 \\
\hline C & 18 & 29 & 19,20 & 2,11 & 15,79 & 23,24 \\
& 28 & 28 & 18,65 & 2,06 & 15,31 & 22,22 \\
& 38 & 21 & 18,69 & 2,36 & 15,02 & 23,24 \\
& 48 & 20 & 18,90 & 2,55 & 14,79 & 23,14 \\
\hline D & 18 & 104 & 20,52 & 1,86 & 16,43 & 23,82 \\
& 28 & 106 & 20,51 & 1,91 & 16,43 & 23,82 \\
& 38 & 137 & 20,01 & 2,17 & 15,23 & 23,82 \\
& 48 & 137 & 19,94 & 2,16 & 15,23 & 23,82 \\
\hline
\end{tabular}

N: sayı, Ort: ortalama, SS: standart sapma, Min: minimum, Maks: maksimum

Tablo 4. Mineralizasyon ve erüpsiyon aşamalarına göre dişlerin ikili karşılaşııma sonuçları ( $p$ değerleri)

\begin{tabular}{|l|l|l|}
\hline Dişler & Mineralizasyon & Erüpsiyon \\
\hline 18 ile 28 & 1,000 & 1,000 \\
\hline 38 ile 48 & 1,000 & 1,000 \\
\hline 18 ile 48 & $0,003^{*}$ & $0,004^{*}$ \\
\hline 28 ile 38 & $<0,001^{*}$ & $0,011^{*}$ \\
\hline 18 ile 38 & $0,004^{*}$ & $0,004^{*}$ \\
\hline 28 ile 48 & $<0,001^{*}$ & $0,011^{*}$ \\
\hline
\end{tabular}

${ }^{*} p<0,05$

Tablo 5.18 yaş sınııı için belirlenen eşik değerlere göre yöntemlerin ayrı ayrı ve birlikte kullanımı ile elde edilen performans ölçüleri

\begin{tabular}{|c|c|c|c|c|}
\hline Diş & Performans Ölçüsü & Mineralizasyon & Erüpsiyon & $\begin{array}{l}\text { Mineralizasyon } \\
\text { ve Erüpsiyon }\end{array}$ \\
\hline 18 & $\begin{array}{l}\text { Eşik aşama } \\
\text { Duyarlılık ( } \geq 18 \text { yaş) } \\
\text { Seçicilik ( }<18 \text { yaş) } \\
\text { AUC } \\
\text { LR+ } \\
\text { LR- }\end{array}$ & $\begin{array}{l}\geq \mathbf{H} \\
74,38 \% \\
93,43 \% \\
0,908 \\
11,3212 \\
0,2742 \\
\end{array}$ & \begin{tabular}{|l|}
$\geq \mathbf{B}$ \\
$88,75 \%$ \\
$73,01 \%$ \\
0,873 \\
3,2883 \\
0,1541 \\
\end{tabular} & $\begin{array}{l}\geq \text { H ve } \geq \text { B } \\
73,13 \% \\
93,77 \% \\
0,885 \\
11,7384 \\
0,2866\end{array}$ \\
\hline 28 & $\begin{array}{l}\text { Eşik aşama } \\
\text { Duyarlıık ( } \geq 18 \text { yaş) } \\
\text { Seçicilik (<18 yaş) } \\
\text { AUC } \\
\text { LR+ } \\
\text { LR- }\end{array}$ & $\begin{array}{l}\mathbf{~ H} \\
75,00 \% \\
90,31 \% \\
0,886 \\
7,7399 \\
0,2768 \\
\end{array}$ & \begin{tabular}{|l|}
$\geq \mathbf{B}$ \\
$88,75 \%$ \\
$72,32 \%$ \\
0,867 \\
3,2063 \\
0,1556 \\
\end{tabular} & $\begin{array}{l}\geq \mathbf{H} \text { ve } \geq \mathbf{B} \\
73,75 \% \\
91,00 \% \\
0,872 \\
8,1944 \\
0,2885 \\
\end{array}$ \\
\hline 38 & $\begin{array}{l}\text { Eşik aşama } \\
\text { Duyarlıık ( } \geq 18 \text { yaş) } \\
\text { Seçicilik (<18 yaş) } \\
\text { AUC } \\
\text { LR+ } \\
\text { LR- }\end{array}$ & $\begin{array}{l}\geq \mathbf{G} \\
88,13 \% \\
82,01 \% \\
0,914 \\
4,8988 \\
0,1447 \\
\end{array}$ & $\begin{array}{l}\geq \mathbf{C} \\
76,25 \% \\
87,54 \% \\
0,865 \\
6,1196 \\
0,2713 \\
\end{array}$ & $\begin{array}{l}\mathbf{Z} \mathbf{\text { G ve }} \geq \mathbf{C} \\
75,00 \% \\
89,62 \% \\
0,875 \\
7,2254 \\
0,2790 \\
\end{array}$ \\
\hline 48 & $\begin{array}{l}\text { Eşik aşama } \\
\text { Duyarlıık ( } \geq 18 \text { yaş) } \\
\text { Seçicilik (<18 yaş) } \\
\text { AUC } \\
\text { LR+ } \\
\text { LR- }\end{array}$ & $\begin{array}{l}\geq \mathbf{G} \\
90,00 \% \\
81,66 \% \\
0,918 \\
4,9073 \\
0,1225 \\
\end{array}$ & $\begin{array}{l}\geq \mathbf{C} \\
75,00 \% \\
87,20 \% \\
0,873 \\
5,8594 \\
0,2867 \\
\end{array}$ & $\begin{array}{l}\geq \mathbf{G} \text { ve } \geq \mathbf{C} \\
73,75 \% \\
88,24 \% \\
0,877 \\
6,2713 \\
0,2975 \\
\end{array}$ \\
\hline
\end{tabular}

\section{TARTIŞMA}

Diş gelişimi kemik gelişimine göre beslenme yetersizlikleri veya hastalıklar gibi dış faktörlerden daha az etkilendiği için kronolojik yaşın güvenilir bir göstergesidir. ${ }^{24,25}$ İkinci molarların gelişiminin yaklaşık olarak 14 yaşında tamamlanmasından sonra yaş tahmini için mevcutsa üçüncü molarlar kullanılabilir. ${ }^{26}$ Üçüncü molarlar; gelişimsel ve morfolojik olarak dentisyonda en çok varyasyon gösteren diş olmasına rağmen, el-bilek kemikleri ve sekonder cinsiyet özelliklerinin oluşumunun tamamlandığı dönemde gelişimsel belirteç olarak değerli bilgiler sağlamaktadır. ${ }^{19,27}$

Üçüncü molarlar konjenital ya da kazanılmış olarak eksik olabileceği veya morfolojik / pozisyon anomalileri gibi nedenlerle değerlendirme yapılamayan durumlarla sık karşılaşılabileceği için, çalışmamızda tüm üçüncü molarlar incelenmiştir.

18 yaş tahmini amacıyla diş gelişiminin değerlendirildiği çalışmalarda çeşitli yöntemler ve istatistiksel yaklaşımlar kullanılmıştır. ${ }^{14-16,19-21,28-31}$ Çalışmamızda önceki çalışmalarla benzer şekilde hem mineralizasyon hem de erüpsiyon aşamalarında aynı arklarda sağ-sol farkı bulunmamıştır. ${ }^{16,28,32-36}$ Bununla birlikte, her iki gelişim sürecinde mandibula ve maksilla arasında istatistiksel olarak anlamlı farklılıklar saptanmıştır. Dişlerin formasyon tempoları arklar arasında farklılık göstermektedir. ${ }^{19} \mathrm{Bu}$ farklılıklar genel olarak, üçüncü molarlar haricindeki dişlerin mineralizasyon ve erüpsiyonunun mandibulada daha hızlı olduğu yönündedir. ${ }^{32,37}$ Üçüncü molarlarda ise formasyon ${ }^{34,38}$ ve erüpsiyon 16,38,39 bakımından arklar arasında fark bulmayan çalışmaların yanı sıra, bulgularımızla uyumlu olarak mineralizasyonun maksillada, ${ }^{19,32,35}$ erüpsiyonun ise mandibulada ${ }^{40-42}$ daha hızlı olduğunu rapor eden çalışmalar mevcuttur. Orhan ve ark. ${ }^{43}$ ve Uzuner ve ark. ${ }^{44}$ istatistiksel olarak anlamlı bir fark saptamamakla birlikte maksiller üçüncü molar mineralizasyonun mandibular üçüncü molarlardan daha ileri olduğunu bulmuşlardır. Mincer ve ark. ${ }^{19}$ mineralizasyondaki farkın iki arktaki farklı kontrol mekanizmalarını yansıttığını belirtmişlerdir. Haavikko ve ark. ${ }^{32}$ ise bu farkı, maksiller üçüncü molarların mandibular dişlere göre gelişim için daha fazla boş alana sahip olmasına atfetmişlerdir. Dişlerin alveolar erüpsiyon ve klinik erüpsiyonu anında formasyon aşamalarının araştırıldığı çalışmada bu iki gelişim sürecinin her zaman aynı dizide olmadığı bulunmuştur. ${ }^{32}$ Çalışmamızda maksiller üçüncü molarların mandibular dişlere göre mineralizasyonda öndeyken erüpsiyonda geride olması bu sonucu desteklemektedir. 
Çalışmamızda 18 yaşı ayırt etmek için belirlenen eşik aşamalar, arklar arasında gözlenen farkılıkları yansıtmıştır. Sol mandibular üçüncü molarlar için belirlenen mineralizasyon eşik aşaması G'nin 18 yaşı ayırt etmede duyarlılığı, seçiciliği ve doğruluğu sırasıyla $\% 88$, \%82 ve \%91 bulunmuştur. Çeşitli populasyonlarda mandibular üçüncü molarlarda 18 yaş sınırıyla ilgili çoğunlukla $\mathrm{H}$ aşaması değerlendirilmiş ve $\mathrm{H}$ eşik aşamasının test edildiği çalışmaların meta-analizinde; yöntemin duyarlılığı \%51, seçiciliği \%96,9 ve doğruluğu \%71 bulunmuştur. ${ }^{45}$ Bu performans ölçüleri, $\mathrm{H}$ aşaması ile 18 yaşın altındaki bireylerin \%97 oranında doğru belirlendiğini ancak 18 yaş üstü bireylerin yarısının yanlış belirlendiğini göstermektedir. Çalışmamıza benzer şekilde eşik aşama $\mathrm{G}$ olarak seçildiğindeyse, $\mathrm{H}$ aşamasına göre seçicilikte azalma, duyarlııı ve doğrulukta artış görülmüştür. ${ }^{15,46}$ Cameriere ve ark. ${ }^{15} \mathrm{G}$ eşik aşaması için duyarlılık, seçicilik ve doğruluğu sırasıyla $\% 75$, \%90 ve \%83 olarak rapor etmişlerdir. Çalışmaların bulguları arasındaki farklar; popülasyon, gözlemci, örneklem boyutu ve dağılımındaki farklılıklardan kaynaklanmış olabilir.

Erüpsiyon aşamalarına dayalı yöntemler ile 18 yaş sınırını değerlendiren sınırlı sayıda çalışma bulunmaktadır. ${ }^{16,28,33,36}$ Üçüncü molarlardan birinin tamamen sürdüğü bir bireyin en az 18 yaşında olma olasılığı, Caldas ve ark.'nın ${ }^{33}$ çalışmasında \%98-100, Yusof ve ark.'nın ${ }^{28}$ çalışmasında kadınlarda \%86-88 ve erkeklerde \%92-96, MR üzerinde yapılan Widek ve ark.'nın ${ }^{36}$ çalışmasında ise \%90-96 arasında bulunmuştur. Bir başka çalışmada bu olasılık, sol mandibular molar için kadınlarda \%85 ve erkeklerde \%80, tüm üçüncü molarların tamamen sürmesi durumunda ise kadınlarda \%85 ve erkeklerde \%98 olarak rapor edilmiştir. ${ }^{16} \mathrm{Bu}$ çalışmalarda değerlendirilen üçüncü molarların tam erüpsiyonu, 18 yaşı ayırt etmek için D eşik aşamasına tekabül ederken çalışmamızda maksiller molarlar için B ve mandibular molarlar için C eşik aşamaları belirlenmiştir. Yusof ve ark. ${ }^{28}$ bir bireyin 18 yaşından büyük olma olasılığını, sol maksiller molarlar B aşamasında ise kadınlarda \%33 ve erkeklerde $\% 12$ olarak bulmuşlardır. Aynı çalışmada, sol mandibular molarlar C aşamasında ise bu olasılık kadınlarda \%52 ve erkeklerde \%42; Widek ve ark.'nın ${ }^{36}$ çalışmasında ise $\% 83$ olarak bildirilmiştir. Bu çalışmalarda verilen olasılıklar, test sonucu pozitif olan bir bireyin 18 yaş ve üstü olma olasılığını ifade eden pozitif tahmini değerlerdir (PPV, positive predictive value). PPV, prevalanstan etkilenmekte ve yanlış negatif ile yanlış pozitif değerleri hesaba katmamaktadır. ${ }^{14}$ Çalışma- mızda ise bu çalışmalardan farklı bir istatistiksel yaklaşımla, belirlenen erüpsiyon eşik aşamalarının 18 yaşı ayırt etmede doğruluğu test edilmiştir ve prevalanstan etkilenmeyen, pozitif ve negatif test sonucunun olasıllğını gösteren LR+ ve LR- değerleri hesaplanmıştır. Bu nedenle doğrudan karşılaştırılabilir sonuçlar olmamasına rağmen, erüpsiyon yöntemi $L R+$ değerlerine göre 18 yaş tahmininde önceki çalışmalardan daha iyi sonuç vermiştir. $L R+>1$, pozitif bir sonucun (bireyin yetişkin olarak belirlenmesi) doğru olma olasılığını gösterir ve bu değer ne kadar büyükse sonucun doğru olma olasılığı o kadar yüksektir. Maksiller üçüncü molarlarda LR+ değerleri, erüpsiyon yöntemiyle yaklaşık 4 pozitif sonuçtan birinde yanlış pozitif (çocuğun yetişkin olarak belirlenmesi) sonuç elde edileceğini göstermektedir. Mandibular üçüncü molarlarda ise yaklaşık 7 pozitif sonuçtan birinin yanlış olacağı, bir başka deyişle her yanlış pozitif için en az altı doğru pozitif elde edileceği anlamına gelmektedir. Diğer performans ölçüleri değerlendirildiğinde, maksiller üçüncü molarların (sol) B eşik aşaması ile \%89 duyarlılık ve \%72 seçicilik elde edilirken, mandibular üçüncü molarların (sol) C eşik aşaması ile \%76 duyarlılık ve \%88 seçicilik elde edilmiştir. Ayrıca tüm üçüncü molarlarda erüpsiyon eşik aşamaları 18 yaş tahmininde \%87 doğruluk sağlamıştır. Bu oran, mineralizasyon yönteminde daha yüksek olup dişlere göre \%89-92 arasında değişmiştir. Erüpsiyonun çevresel faktörler nedeniyle mineralizasyondan daha fazla varyasyon göstermesinden kaynaklanan, literatürle $e^{25,36,38}$ uyumlu bu sonuca karşın, erüpsiyon yönteminin performansı beklenenden yüksek bulunmuştur.

Erüpsiyon ve mineralizasyon yöntemlerinin kombinasyonu, tek başına mineralizasyon yönteminin performans ölçüleriyle karşılaştırıldığında maksiller molarlar (sol) için duyarlılıkta yaklaşık \%1 düşüş, seçicilikte \%0,7 artış; mandibular molarlar (sol) için duyarlılıkta yaklaşık \%13 düşüş, seçicilikte \%8 artış gözlenmiştir. Kombinasyon, tek başına erüpsiyon yönteminin performans ölçüleriyle karşılaştırıldığında ise maksiller molarlar için duyarlılıkta yaklaşık \%15 düşüş, seçicilikte \%19 artış; mandibular molarlar için duyarlılıkta yaklaşık \%1 düşüş, seçicilikte \%2 artış görülmüştür. Bununla birlikte her iki yöntemin kombinasyonu ile elde edilen doğruluk, tek başına erüpsiyon yöntemine göre yaklaşık \%1 artarken, tek başına mineralizasyon yöntemine göre \%1-4 oranında düşmüştür.

Sonuç olarak, 18 yaşın ayırt edilmesinde mineralizasyon yöntemi yüksek düzeyde doğruluk sağlarken, 
erüpsiyon yöntemi ve her iki yöntemin kombinasyonu orta düzeyde doğruluk göstermiştir. Üçüncü molarların erüpsiyon aşamaları, mineralizasyon aşamaları ile yapıIan 18 yaş tahmin performansına anlamlı bir katkıda bulunmamıştır. Bununla birlikte her iki yöntem değerlendirme kolaylığı bakımından adli uygulamalarda destekleyici metot olarak yararlı olabilir. Ancak yöntemlerin geçerliliği farklı örneklemlerde test edilmelidir.

NOT: Calışmada herhangi bir yazar, kurum ya da kuruluş ile çıkar çatışması içerisinde bulunmamaktadır. Makale daha önce hiçbir yerde yayınlanmamış ve yayınlanmak üzere işlem görmemektedir

\section{KAYNAKLAR}

1. Arslan MM, Çekin N, Akçan R, Saylak E. Hatay Ağır Ceza ve Asliye Hukuk Mahkemelerine 2007 yılında yansıyan yaş tespiti davalarının incelenmesi. Adli Tıp Dergisi 2008;22:8-13.

2. Karaman F. Adli diş hekimliğinde güncel yaklaşımlar. Atatürk Üniv Diş Hek Fak Derg 2020; 30: 492-8.

3. Franklin D, Flavel A, Noble J, Swift L, Karkhanis S. Forensic age estimation in living individuals: methodological considerations in the context of medico-legal practice. Res Rep Forensic Med Sci 2015:5;53-66.

4. Harunoğulları M. Suriyeli sığınmacı çocuk işçiler ve sorunları: Kilis örneği. Göç Derg 2016;3:29-63.

5. Timme M, Steinacker JM, Schmeling A. Age estimation in competitive sports. Int J Legal Med 2017;131:225-33.

6. Baransel Isır A. Adli hekimlikte yaş tayini. Klinik gelişim dergisi Adli Tıp Özel Sayısı 2009;2:114-21.

7. Schmelling A, Grundmann C, Fuhrmann A, Kaatsch $\mathrm{H}-\mathrm{J}$, Knell B, Ramsthaler F, Reisinger W, Riepert T, Ritz-Timme S, Rösing FW, Rötzscher K, Geserick G. Criteria for age estimation in living individuals. Int J Legal Med 2008;122:457-60.

8. Senn DR, Stimson PG. Forensic Dentistry, 2nd ed., Taylor \& Francis, Boca Raton, 2010.

9. Galic I, Vodanovic M, Cameriere R, Nakas E, Galic E, Selimovic E, Brkic H. Accuracy of Cameriere, Haavikko, and Willems radiographic methods on age estimation on Bosnian-Herzegovian children age groups 6-13. Int J Legal Med 2011;125:31521.

10. De Salvia A, Calzetta C, Orrico M, De Leo D. Third mandibular molar radiological development as an indicator of chronological age in a European population. Forensic Sci Int 2004;146: 9-12.

11. Schmidt S, Schmeling A, Zwiesigk P, Pfeiffer $H$,
Schulz R. Sonographic evaluation of apophyseal ossification of the iliac crest in forensic age diagnostics in living individuals. Int J Legal Med 2011;125:271-6.

12. Kasper KA, Austin D, Kvanli AH, Rios TR, Senn DR. Reliability of third molar development for age estimation in a Texas hispanic population: a comparison study. J Forensic Sci 2009;54: 651-57,

13.5237 sayılı Türk Ceza Kanunu (2004). Resmi Gazete 2004;25611.

14. Liversidge HM, Marsden $\mathrm{PH}$. Estimating age and the likelihood of having attained 18 years of age using mandibular third molars. $\mathrm{Br}$ Dent J 2010;209:E13.

15. Cameriere R, Ferrante L, De Angelis D, Scarpino F, Galli $F$. The comparison between measurement of open apices of third molars and Demirjian stages to test chronological age of over 18 year olds in living subjects. Int J Legal Med 2008;122:493-97.

16. Gambier A, Rérolle C, Faisant M, Lemarchand J, Paré $A$, Saint-Martin P. Contribution of third molar eruption to the estimation of the forensic age of living individuals. Int J Legal Med 2019;133:62532.

17. Demirjian A, Goldstein $H$, Tanner JM. A new system of dental age assessment. Hum Biol 1973;45:211-27.

18. Olze A, Bilang D, Schmidt S, Wernecke K-D, Geserick G, Schmeling A. Validation of common classification systems for assessing the mineralization of third molars. Int J Legal Med 2005;119:22-6.

19. Mincer H, Harris E, Berryman H. The A.B.F.O. study of third molar development and its use as an estimator of chronological age. J Forensic Sci 1993;38:379-90.

20. Knell B, Ruhstaller P, Prieels F, Schmeling A. Dental age diagnostics by means of radiographical evaluation of the growth stages of lower wisdom teeth. Int J Legal Med 2009;123:465-9.

21. Gunst K, Mesotten K, Carbonez A, Willems G. Third molar root development in relation to chronological age: a large sample sized retrospective study. Forensic Sci Int 2003;136:52-7.

22. Olze $A$, van Niekerk $P$, Ishikawa $T$, Zhu BL, Schulz $R$, Maeda $H$, Schmeling A. Comparative study on the effect of ethnicity on wisdom tooth eruption. Int J Legal Med 2007;121:445-8.

23. Landis JR, Koch GG. The measurement of observer agreement for categorical data. Biometrics 1977;33:159-74. 
24. Garn SM, Lewis AB, Kerewsky RS. Genetic, nutritional, and maturational correlates of dental development. J Dent Res 1965;44:228-42.

25. Saunders S, DeVito C, Herring A, Southern R, Hoppa R. Accuracy tests of tooth formation age estimations for human skeletal remains. Am J Phys Anthropol 1993;92:173-88.

26. Canger EM, Arslan S. Adli diş hekimliğinde radyolojinin kullanımı. Atatürk Üniv Diş Hek Derg 2013;23:252-60.

27. Blankenship JA, Mincer $\mathrm{HH}$, Anderson KM, Woods MA, Burton EL. Third molar development in the estimation of chronological age in American blacks as compared with whites. J Forensic Sci 2007;52:428-33.

28. Mohd Yusof MY, Cauwels R, Martens L. Stages in third molar development and eruption to estimate the 18-year threshold Malay juvenile. Arch Oral Biol 2015;60:1571-6.

29. Karadayi B, Kaya A, Afsin H, Ozaslan A, Çetin G. The usage of third molars to determine legally relevant age thresholds in Turkey. Aust J Forensic Sci 2015;47:275-82.

30. Scheurer E, Quehenberger F, Mund MT, Merkens $\mathrm{H}$, Yen K. Validation of reference data on wisdom tooth mineralization and eruption for forensic age estimation in living persons. Int J Legal Med 2011;125:707-15.

31. Acharya AB, Bhowmik B, Naikmasur VG. Accuracy of identifying juvenile/adult status from third molar development using prediction probabilities derived from logistic regression analysis. J Forensic Sci 2014;59:665-70.

32. Haavikko K. The formation and the alveolar and clinical eruption of the permanent teeth. An orthopantomographic study. Suom Hammaslaak Toim 1970;66:103-70.

33. Caldas IM, Julio P, Simoes RJ, Matos E, Afonso A, Magalhaes T. Chronological age estimation based on third molar development in a Portuguese population. Int J Legal Med 2011;125:235-43.

34. Karataş OH, Öztürk F, Dedeoğlu N, Çolak C, Altun O. Radiographic evaluation of third-molar development in relation to the chronological age of Turkish children in the southwest eastern Anatolia region. Forensic Sci Int 2013;232:238.e1-238.e5.

35. Willershausen B, Loffler N, Schulze R. Analysis of 1202 orthopantograms to evaluate the potential of forensic age determination based on third molar developmental stages. Eur J Med Res 2001;6:37784.
36. Widek T, Genet P, Merkens $H$, Boldt J, Petrovic A, Vallis J, Scheurer E. Dental age estimation: The chronology of mineralization and eruption of male third molars with 3T MRI. Forensic Sci Int 2019;297:228-35.

37. Barrett MJ. Dental observations on Australian aborigines: tooth eruption sequence. Aust Dent J 1957;2:217-27.

38. Karadayi B, Kaya A, Kolusayın MO, Karadayi S, Afsin $H$, Ozaslan A. Radiological age estimation: based on third molar mineralization and eruption in Turkish children and young adults. Int J Legal Med 2012;126:933-42.

39. Shaweesh AI. Timing of clinical eruption of third molars in a Jordanian population. Arch Oral Biol 2016;72:157-63.

40. Odusanya SA, Abayomi IO. Third molar eruption among rural Nigerians. Oral Surg Oral Med Oral Pathol 1991;7:151-4.

41. Hassanali J. The third permanent molar eruption in Kenyan Africans and Asians. Ann Hum Biol 1985; 12:517-23.

42. Karkhanis S, Mack P, Franklin D. Dental age estimation standards for a Western Australian population. Forensic Sci Int 2015;257:509.e1509.e9, DOI: 10.1016/j.forsciint.2015.06.021

43. Orhan K, Ozer L, Orhan AI, Dogan S, Paksoy CS. Radiographic evaluation of third molar development in relation to chronological age among Turkish children and youth. Forensic Sci Int 2007; 165:46-51.

44. Uzuner F, Kaygısız E, Darendeliler N, Yeniay A. Bir Türk popülasyonunda üçüncü molar dişlerin gelişiminin radyografik olarak değerlendirilmesi: yaş, cinsiyet ve çene karşılaştırması. Acta Odontol Turc 2015;32:130-5.

45. Haglund $M$, Mörnstad $H$. A systematic review and meta-analysis of the fully formed wisdom tooth as a radiological marker of adulthood. Int J Legal Med 2019;133:231-9.

46. Antunovic M, Galic I, Zelic K, Nedeljkovic N, Lazic E, Djuric M, Cameriere R. The third molars for indicating legal adult age in Montenegro. Legal Med 2018;33:55-61.

\section{Sorumlu Yazarın Yazışma Adresi}

Dr. Öğr. Üy. Nursel AKKAYA

Hacettepe Üniversitesi Diş Hekimliği Fakültesi Ağız, Diş ve Çene Radyolojisi A.D.

Sihhiye, Ankara

Tel: 03123052205

E-mail: ynursel@hacettepe.edu.tr 